\section{Kidney \\ Blood Pressure Research}

DOI: 10.1159/000355739

Accepted: October 30, 2013 (c) 2013 S. Karger AG, Basel www.karger.com $/ \mathrm{kbr}$

1423-0143/13/0376-0588 \$38.00/0

This is an Open Access article licensed under the terms of the Creative Commons AttributionNonCommercial 3.0 Unported license (CC BY-NC) (www.karger.com/OA-license), applicable to the online version of the article only. Distribution permitted for non-commercial purposes only.

Review

\title{
Hepatorenal Syndrome and Novel Advances in its Management
}

\author{
Fabrizio Fabrizi ${ }^{a} \quad$ Alessio Aghemo $^{b}$ Piergiorgio Messa ${ }^{a}$ \\ aDivision of Nephrology, bDivision of Gastroenterology, Maggiore Hospital and IRCCS Foundation, \\ Milano, Italy
}

\section{Key Words}

Hepatorenal syndrome $\cdot$ Terlipressin $•$ Cirrhosis $•$ Vasoconstrictors $•$ Survival

\begin{abstract}
Hepatorenal syndrome is a complication of end stage liver disease. It is a unique form of functional renal failure related to kidney vasoconstriction in the absence of underlying kidney pathology. Hepatorenal syndrome is classified into 2 types: type-1 HRS shows a rapid and progressive decline in renal function with a very poor prognosis (median survival of about 2 weeks); type- 2 HRS has a more stable kidney failure, with a median survival of 6 months; its main clinical manifestation is refractory ascites. The most appropriate therapy for HRS is liver transplantation but only a minority of HRS patients undergo the procedure due to the high mortality; survival among liver transplant recipients is lower in HRS than among their counterparts without HRS. A large body of evidence, based on observational studies and randomized controlled trials, has been accumulated in the last decade showing that terlipressin represents a milestone in the management of HRS. According to our metaanalysis of randomized trials comparing terlipressin vs. placebo (five trials, $n=243$ patients), the pooled rate of patients who reversed HRS by terlipressin was 8.09 (95\% CI, 3.52; 18.59) $(P<0.001)$. Among vasoconstrictors, terlipressin (a V1 vasopressin agonist) is the most widely used; however, noradrenaline is another good choice. Vasoconstrictor drugs alone or with albumin reduce mortality compared with no intervention or albumin (RR of mortality, 0.82 ; $95 \%$ Confidence Intervals, $0.70 ; 0.96)(P<0.01)$. Two series of patients with HRS recurrence after the first treatment have recently shown that long-term therapy with terlipressin and albumin is beneficial as a bridge to liver transplant. Nevertheless, recovery of renal function can be achieved in less than $50 \%$ of patients with HRS after terlipressin use and the recovery of renal function may also be partial in patients who are defined full responders. Renal replacement therapy should not be considered a first-line therapy for HRS Clinical trials are under way in order to assess efficacy and safety of novel therapeutic agents for the treatment of type-1 and type-2 HRS.
\end{abstract}




\section{Kidney Blood Pressure Research}

\section{Historical perspective}

The association between liver disease and renal failure had been known for more than a hundred years. Frerichs was the first investigator who reported on the occurrence of oliguria in patients with ascites since 1877 [1]. The term 'hepatorenal syndrome' was used in 1939 to describe the occurrence of renal failure after biliary surgery in patients showing a pathological pattern of acute tubular necrosis or tubular interstitial nephritis [2-3]. Later on, the term 'hepatorenal syndrome' was used to report on any kind of simultaneous impairment of liver and kidney function. The presence of low sodium excretion in the urine of patients with HRS was discovered by Hecker and Sherlock in 1956 [4]. The functional nature of this renal failure was emphasized by Koppel et al. [5] who proved in the 1960s that kidneys obtained from patients who dead with HRS could be transplanted in patients with renal failure of different aetiology, since these kidneys could recover their function after transplant. The first consensus definition on the optimal criteria to define HRS was agreed upon at the 1994 meeting of the International Ascites Club [6] but new criteria were developed by the IAC with a meeting held in San Francisco in 2006 [7].

\section{Epidemiology and clinical manifestations of HRS}

HRS is a potentially reversible form of renal failure that occurs in patients with cirrhosis and ascites as well as in patients with acute liver failure. In cirrhotic patients with ascites, the most common causes of acute renal failure are: pre-renal (around 37\%), acute tubular necrosis (around 42\%), and post-renal failure (0.3\%); HRS is around 20\% [8-9]. The cumulative probability of HRS in patients with cirrhosis and ascites is equal to $18 \%$ after 1 year, rising to $39 \%$ at 5 years [10].

Predictors for the development of HRS have been suggested to include liver size, serum sodium concentration $(<133 \mathrm{mEq} / \mathrm{L})$, increased plasma renin activity $(>3.5 \mathrm{ng} / \mathrm{mL} / \mathrm{h})$, and increased resistive index of renal arcuate and interlobar arteries $(>0.7$ by Doppler ultrasound). Some investigators noted the role of total bilirubin and prothrombin time (major determinants of the Child-Pugh score) as significant and independent predictors of HRS [11-12].

HRS type 1 is an acute disease often induced by precipitating factors such as bacterial infections (57\%), gastrointestinal hemorrhage (36\%), and large volume paracentesis without plasma expansion (7\%) [11-12]. Spontaneous bacterial peritonitis represents the most important bacterial infection associated with HRS occurrence and it occurs in many patients despite a rapid resolution of the infection with non-nephrotoxic antibiotics. Renal failure can be precipitated in cirrhotic patients with ascites by all types of bacterial infections; in most cases renal failure is transient and recovers after the resolution of the infection but, in some cases, an acute renal failure with the hallmarks of type-1 HRS can occur. HRS commonly develops in patients with advanced cirrhosis; thus, HRS patients have jaundice and other stigmata of chronic liver disease such as spider nevi, palmar erythema, and finger clubbing. Further clinical manifestations include splenomegaly, ascites, hepatic encephalopathy, and bleeding. The urine output is reduced particularly in type-1 HRS, and low arterial blood pressure usually occurs. In patients with type-1 HRS the main clinical presentation is overt acute renal failure whereas the degree of the impairment of renal failure is less severe and more stable over time in type- 2 HRS patients.

In contrast, HRS type 2 is not precipitated by acute events and is characterized by a progressive deterioration of renal function related to the degree of portal hypertension. Type-2 HRS develops spontaneously in many patients with cirrhosis and ascites and represents the real functional renal failure associated with cirrhosis. Patients with type-2 HRS are predisposed to develop type-1 HRS following infections or other trigger events. The patho-physiological differences between type- 1 and type- 2 HRS are not fully elucidated and this is a point of intense research [11-12]. 


\section{Kidney Blood Pressure Research}

\section{Pathogenesis of HRS}

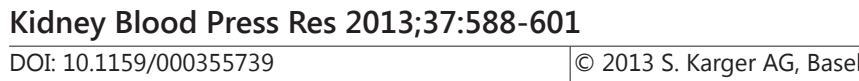

Published onlıne: December 05, 2013

www.karger.com/kbr

Fabrizi/Aghemo/Messa: Therapy of Hepato-Renal Syndrome

The pathogenesis of HRS is not completely understood but various hypotheses linking the alterations of renal haemodynamics and ascites formation have been made [13-14]. The most popular hypothesis is the 'arteral vasodilation hypothesis', proposed by Schrier et al. in 1988 [15], the development of HRS is associated with the circulatory changes seen in cirrhosis with portal hypertension, including splanchnic arterial vasodilation. Splanchnic vasodilation may result in effective arterial underfilling and is clinically manifested by arterial hypotension. In the early stage of cirrhosis, the increase in heart rate and cardiac output compensates the reduction of the effective blood volume; as the liver disease progresses leading to a further impairment in portal hypertension and hepatic insufficiency, there is activation of the systemic endogenous vasoconstrictor systems (the sympathetic nervous system, the reninangiotensin- aldosterone system, and the non-osmotic release of vasopressin). The activation of these systems explains some functional abnormalities at kidney level such as renal sodium retention leading to ascites, and renal water retention leading to hyponatremia. Thus, vasoconstriction in several vascular regions (including liver and brain) occurs. In the early stage of cirrhosis, an increased activity of systemic and renal vasodilators preserves renal perfusion despite activation of RAAS and SNS. The most important renal vasodilators being kinins, nitric oxide, prostaglandins, and natriuretic peptides. In the late stage of cirrhosis, renal perfusion cannot be maintained because of extreme arterial underfilling causing lower activity of local vasodilators and maximal activation of vasoconstrictors; at this critical point HRS occurs [15].

The most recent advances in the pathogenesis of HRS have given emphasis on the notion that the cardiac output is unable to prevent a severe reduction of effective circulating volume due to the splanchnic arterial vasodilation. Cardiac output may be low, high or normal, but is relatively insufficient to prevent a severe reduction of effective circulating volume due to splanchnic arterial vasodilation in patients having HRS. It is still unclear why cardiac output worsens in end-stage liver disease but the so-called 'cirrhotic cardiomyopathy' has been recently recognized [16]. Cardiac dysfunction reverses 9 to 12 months after LT suggesting that the diseased liver rather than the cause of liver disease is responsible for cardiac dysfunction. Specific cardiac abnormalities have been recognized to describe 'cirrhotic cardiomiopathy', including reduced systolic and diastolic responses to stress stimuli, enlargement of cardiac chambers, electrophysiological repolarisation abnormalities. In addition, other factors such as inflammatory cytokines, nitric oxide, carbon monoxide and other substances evoked by the reaction to bacterial infection have been implicated in the pathogenesis of impaired cardiac function in patients with end-stage liver disease.

Overall, HRS is featured by a marked renal vasoconstriction with a consequent reduction in renal plasma flow and glomerular filtration rate, absence of pathological changes in the kidney tissue and intact activity of renal tubules. Splanchnic arterial vasodilation is thought to be related to an increased activity of endogenous vasodilators due to portal hypertension and/or hepatic failure (including nitric oxide, glucagon, prostacyclin, and endogenous opiates). The relative role of each of them is unclear and probably varies over the different stages of the liver disease (Figure 1).

\section{Diagnosis of HRS}

There are no specific diagnostic tests to distinguish between HRS and other causes of renal failure that may occur in cirrhosis, and the criteria for diagnosing HRS have recently been reviewed by the IAC [7] (Table 1). The most important changes in the revised criteria are as follows: the minor diagnostic criteria are no longer considered essential for the diagnosis of HRS; the ongoing bacterial infections are not an exclusion criteria for the diagnosis of HRS; creatinine clearance is no more considered as a tool for the diagnosis since it offers few advantages in terms of accuracy in the estimation of renal function as compared to the 


\section{Kidney \\ Blood Pressure \\ Research}

Fig. 1.

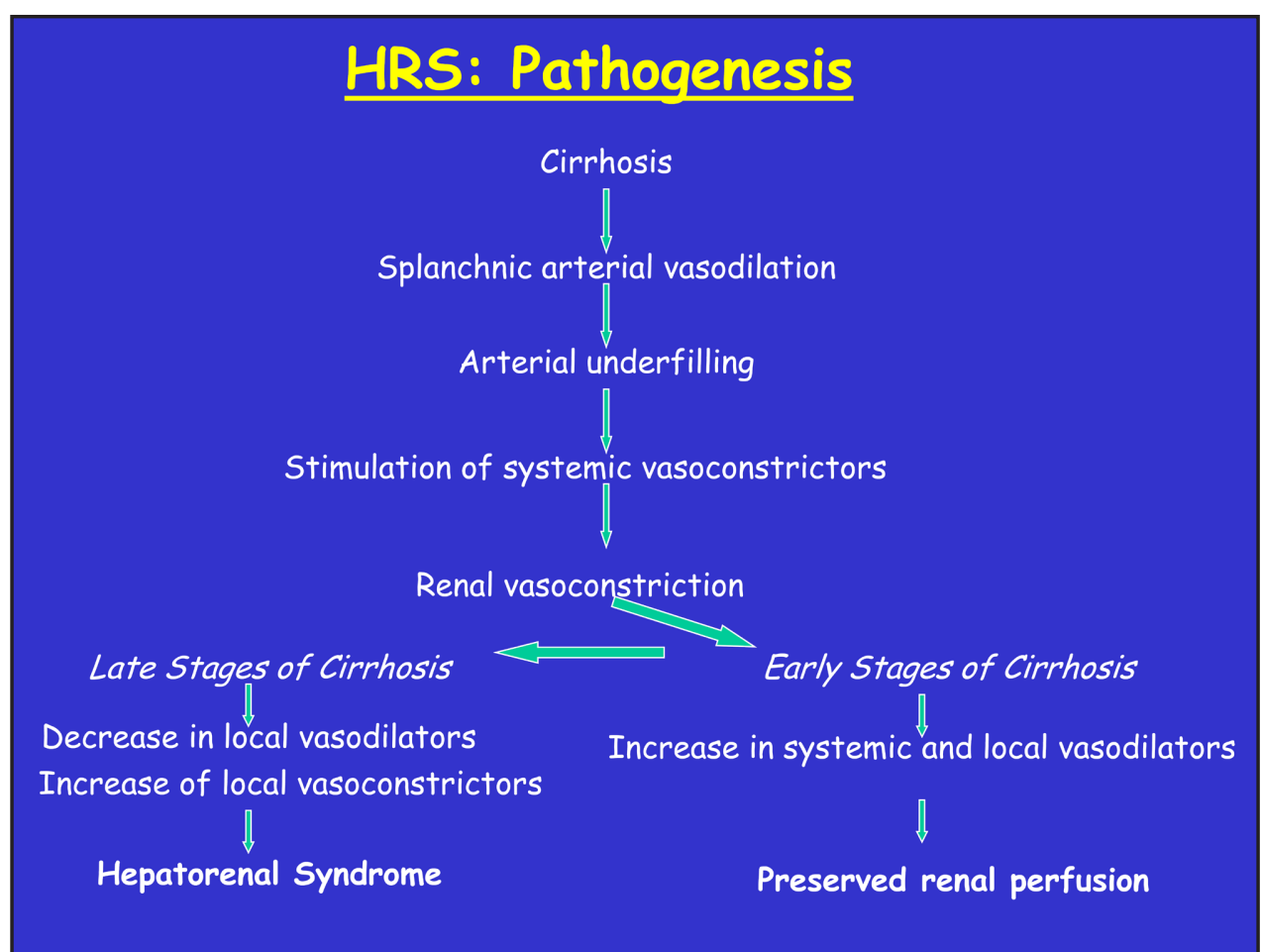

Table 1.

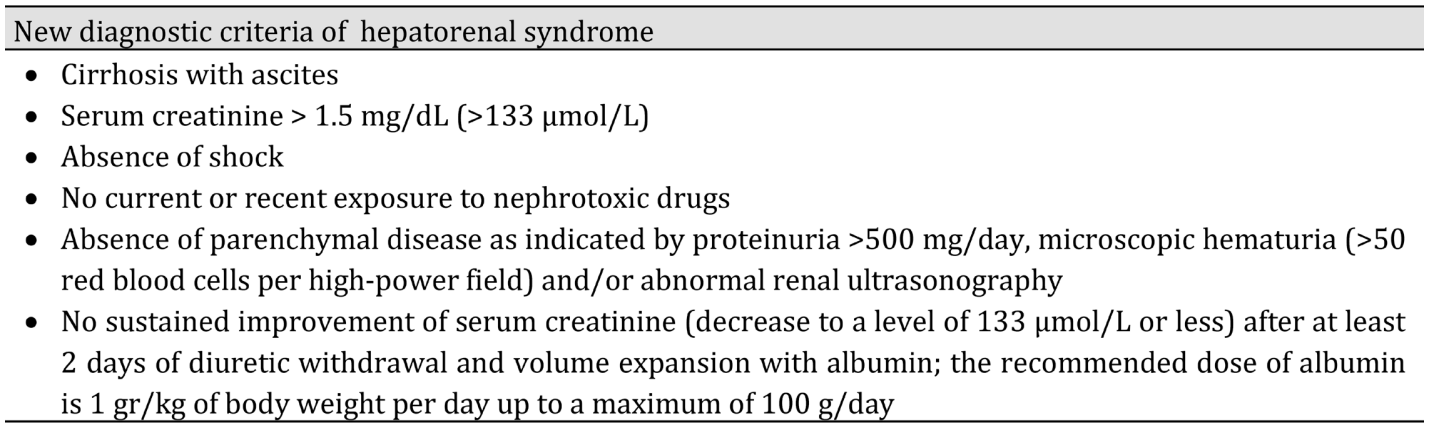

use of serum creatinine. Although various causes of kidney failure in the setting of advanced liver disease exist such as volume depletion, shock (haemorragic or septic shock), exposure to nephrotoxic drugs, or parenchimal renal failure (i.e., glomerulonephritis), renal failure in cirrhosis most commonly occurs in the absence of these factors. Some weakness in the criteria set by the IAC for the diagnosis of HRS may probably exist; as an example, patients with cirrhosis frequently experience acute ischemic tubular necrosis due to slight decreases in arterial pressure (without shock) at various times. A higher susceptibility to ischemia due to renal vascular abnormalities has been noted in cirrhotic patients [17].

HRS is a life-threatening complication of cirrhosis and is classified into 2 types based on the clinical course: type-1 HRS shows a rapid and progressive decline in renal function as measured by a doubling of the baseline serum creatinine to a level greater than $2.5 \mathrm{mg} / \mathrm{dL}$, or a $50 \%$ decline in the baseline creatinine clearance to a level less than $20 \mathrm{~mL} / \mathrm{min}$ in less than 2 weeks. Type-2 HRS patients have an impairment in the renal function as measured by a serum creatinine greater than $1.5 \mathrm{mg} / \mathrm{dL}$ but not meeting the criteria for the type- 1 HRS. Type-2 HRS is a more chronic form and has a corresponding better prognosis. The most important clinical consequence of type-2 HRS is ascites with poor or no response to diuretics (a condition known as refractory ascites). The median survival of a patient with type-1 or 


\section{Kidney Blood Pressure Research}

Fabrizi/Aghemo/Messa: Therapy of Hepato-Renal Syndrome

type-2 HRS is about 2 weeks and 4-6 months, respectively. These survival rates are lower than that observed in patients with ascites and intact kidney function. Spontaneous recovery from HRS is rare unless there is an improvement in liver function.

\section{Outcome of patients with HRS and LT}

The best treatment for HRS is liver transplantation but many patients die before LT because of the short survival associated with HRS, and organ shortage. HRS should be treated before LT in an attempt to improve the renal function as evidence has shown that patients with HRS who receive transplants have more complications and moderately higher mortality rate than those without HRS. Patients with HRS before liver transplant are more likely to be ICU bound (HRS vs. non-HRS; $90 \%$ vs. $33.4 \%$; $P<0.001)$ and require dialysis $(32.2 \%$ versus $1.5 \% ; P<0.001)$ than their counterparts without HRS [18-19]. HRS patients have severely reduced GFR (HRS vs. non-HRS, 19.9 vs. $97.1 \mathrm{~mL} / \mathrm{min} ; P<0.001$ ) and have higher serum levels of bilirubin (17.2 mg/dL vs. $9.37 \mathrm{mg} / \mathrm{dL} ; P=0.007)$ [18-19]. Postoperatively, these patients spend more days in the ICU (HRS vs. non-HRS, 20.8 vs. 4.4; $P=0.001$ ) and have a higher postoperative dialysis (57.9 vs. $11.1 \%$; $P=0.001$ ) requirement [17-18]. Approximately $10 \%$ of patients with HRS will progress to ESRD during the post-operative period as compared with $0.8 \%$ of recipients without HRS [18-19].

Ruiz et al. [20] at the Baylor Regional Liver Transplant Institute identified 130 patients with HRS undergoing LT over a 10-year period (since January 1995 to December 2004) with an overall incidence of 9\%. A total of 13 patients developed type-1 HRS and 117 patients evolved with type- 2 HRS. In the whole group, patient survival rates at 1,3 , and 5 years were $74 \%$, and $68 \%$, and $62 \%$, respectively. Survival was significantly worse when compared to non-HRS patients undergoing LT over the same study period $(P=0.0001)$. According to Distant and Gonwa, 4-year survival among LT recipients was $70 \%$ vs. $60 \%$ in non-HRS and HRS patient groups, respectively [18].

Despite the disappearance of the hemodynamic and neuro-humoral abnormalities by 1 month after LT, glomerular filtration improves only partially, reaching $30-40 \mathrm{~mL} / \mathrm{min}$ by $1-2$ months [21]. Because tacrolimus or cyclosporine may contribute to this impairment of renal function, it has been suggested to delay the administration of these drugs until a recovery of renal function is noted, usually 48-72 hours after liver transplantation.

\section{Pharmacologic treatment of HRS}

Up to 1999, the prognosis of cirrhotic patients developing HRS was very poor with a mortality rate reaching $100 \%$ in some reports, and a median survival time of two weeks from diagnosis. Evidence has been accumulated showing that systemic vasoconstrictors for the treatment of type-1 or -2 HRS have really changed the outcome of these patients [2224]. Systemic vasoconstrictors used for HRS include vasopressin analogues (ornipressin) [25-27], somatostatin analogues (octreotide) [28-31], alpha-adrenergic agonists including midodrine [32] and noradrenaline [33-38]. Medical literature is abundant on clinical studies regarding terlipressin, a vasopressin analogue, for the treatment of HRS [39-56]. In many studies, vasoconstrictors were given in combination with albumin, which probably improves their efficacy [57]. Terlipressin had been licensed first for the management of acute variceal bleeding and has a much greater effect on vascular (V1) than on renal vasopressin receptors (V2). Abundant V1 receptors are present in the splanchnic vasculature causing greater vasoconstriction in the mesenteric circulation than in renal or other vascular systems. The rationale for the administration of terlipressin is to counteract the extreme splanchnic arterial vasodilation in patients with HRS resulting in an improvement of circulatory function (i.e., increase in the effective arterial blood volume), which leads to a suppression of the activity of the vasoconstrictor systems (i.e., renin-angiotensin and sympathetic nervous system) 


\section{Kidney \\ Blood Pressure Research}

Kidney Blood Press Res 2013;37:588-601

\begin{tabular}{l|l}
\hline DOI: 10.1159/000355739 & (c) 2013 S. Karger AG, Basel
\end{tabular}

Published onlıne: December 05, 2013

www.karger.com/kbr

593

and subsequent increase of renal perfusion and glomerular filtration rate. Terlipressin has been used either as an intravenous bolus starting at an initial dose of $0.5 \mathrm{mg}$ every 4-6 $\mathrm{h}$ or continuous intravenous infusion starting at an initial dose of $2 \mathrm{mg} /$ day. In patients with no significant reduction of serum creatinine within 3 days, the initial dose of terlipressin is doubled. The maximal doses of terlipressin used in the treatment of type- 1 HRS are $2 \mathrm{mg}$ every 4-6 hours by intravenous boluses, or $12 \mathrm{mg} /$ day by continuous intravenous infusion, respectively.

\section{Rationale of HRS therapy}

Several studies from various transplant units have convincingly demonstrated that pre-transplant renal function is a major determinant of survival after liver transplantation $[21,58]$. Patients with HRS have a high mortality rate while awaiting transplantation; in addition, the presence of HRS at the time of LT is associated with a poor outcome after LT [18]. The presence of HRS also carries an increased risk of complications post-transplantation, including bleeding, and infections; a greater use of medical resources (longer hospitalizations and prolonged stays in intensive care units) has been calculated [18]. The impact of treatment of HRS before LT on outcome after transplantation has been evaluated by Restuccia et al. [59]. The outcome of patients with HRS $(n=9)$ treated with vasopressin analogues before LT was compared with that of a contemporary control group of patients without HRS $(n=27)$ matched by age, staging of liver disease, and immunosuppressive therapy. Three-year survival probability was not different between the two groups, $100 \% v s$. $83 \%, P=0.15$. No significant differences were found between the two groups with respect to the incidence of impairment of renal function after LT, 22\% (2/9) vs. 30\% (8/27) within the first 6 months after transplantation. Severe infections (22\% vs. 33\%), acute rejection (33\% vs. $41 \%)$, and transfusion requirement $(11 \pm 3 v s .10 \pm 2$ units) were not significantly different between the two groups. The duration of the stay in intensive care units as well as the total duration of the hospitalization were similar between the two groups $(6 \pm 1$ vs. $8 \pm 1$ days, and $27 \pm 4 v s .31 \pm 4$, respectively) ( $P=\mathrm{NS}$ for both) [59].

\section{Therapy of HRS: Vasoconstrictors (Observational studies)}

Many clinicians have started to use terlipressin in patients with HRS but the majority of these studies had small size and uncontrolled design [39-56]. We have previously evaluated efficacy and safety of terlipressin in the treatment of hepatorenal syndrome by a pooled analysis of observational (uncontrolled) studies [60]. The primary outcome (as a measure of efficacy) was the frequency of responder patients (i.e., patients who had reversal of HRS after terlipressin therapy). The secondary outcomes included the frequency of responders who had recurrence of HRS after terlipressin withdrawal. Complete reversal of HRS was defined by a decrease of serum creatinine with a final value $<1.5 \mathrm{mg} / \mathrm{dL}$. Ten clinical studies ( $n=154$ unique patients) were enrolled. The pooled frequency of responder patients after terlipressin therapy was 0.52 (95\% Confidence Intervals, $0.42 ; 0.61)$, according to a randomeffects model. An important drawback of terlipressin therapy is that hepatorenal syndrome recurrence after terlipressin withdrawal is very common, especially in type 2 hepatorenal syndrome [37]. A lower relapse rate (0-5\%) has been reported after vasoconstrictor therapy in HRS type 1 [37]. In our analysis, the frequency of responder patients who showed recurrence of HRS after terlipressin withdrawal was 0.55 (95\% CI, 0.40; 0.69) but evidence on this point was provided in six clinical studies only [60]

Responder patients with recurrence of HRS after terlipressin withdrawal should be treated again and this approach can be effective. Two series ( $n=6$ patients overall) have been recently published on long-term treatment (terlipressin and albumin) of patients with recurring type-1 HRS who are listed with high priority [61-62]. Continuous therapy with 


\section{Kidney Blood Pressure Research}

terlipressin and albumin was effective as a bridge to LT over a period of 2-8 months; no major side-effects were observed during terlipressin use. The outcome after LT was excellent in four patients as they did not develop chronic kidney disease or required renal replacement therapy after LT.

Terlipressin use in clinical practice has been limited by several factors, i.e. it is expensive, is not available in many countries including the United States and can give ischemic sideeffects requiring interruption of treatment [63]. The summary estimate of the rate of patients showing side-effects and drop-outs during terlipressin therapy was 0.25 (95\% CI, 0.18; 0.32) and 0\%, according to our systematic review [60]. HRS patients are prone to develop complications as they show severe dysfunction in several organs in addition to liver and kidney. Terlipressin is probably safer than other vasoconstrictor agents (i.e., ornipressin) but adverse effects during terlipressin therapy had been already noted. Thus, a careful selection of patients and close clinical surveillance during terlipressin therapy are needed. Contraindications to terlipressin use include a history of coronary artery disease, cardiomyopathies, cardiac arrhythmias, cerebrovascular disease, chronic obstructive pulmonary disease, arterial hypertension, and obliterative arterial disease of the lower limbs. The tolerance to terlipressin therapy reported by some authors was probably related to the efforts made to exclude patients with contraindications to treatment.

An important question is prediction of response to terlipressin treatment [22-24]. The most consistent predictor of response to terlipressin and of survival is the baseline serum creatinine, bilirubin, and an increase in mean arterial pressure of $\geq 5 \mathrm{mmHg}$ at day 3 of treatment. Patients who most likely will benefit from terlipressin have earlier onset renal failure (serum creatinine $<3 \mathrm{mg} / \mathrm{dL}$ ). It has been calculated that the cut-off level of serum bilirubin that best predicted response to treatment was $10 \mathrm{mg} / \mathrm{dL}$. As reported below, an early increase in the hyperdynamic circulation (measured by sustained rise in mean arterial pressure) is also important for reversal of HRS. These findings have implications for the management of HRS patients, as it is necessary to start treatment as early as possible. Predictive factors of response in various studies in patients with HRS included baseline Child-Pugh and MELD scores; interestingly, a Child-Pugh score above 13 is predictive of a lack of beneficial effect of terlipressin on renal function. Another independent predictive factor of improvement of renal function in response to terlipressin is younger age and the reasons for this appear unclear [49].

\section{Therapy of HRS: Vasoconstrictors (RCTs)}

More convincing evidence on the efficacy and safety of terlipressin has been provided by some RCTs [40, 53, 56, 64-65]. Systematic reviews of the literature with meta-analyses of RCTs comparing terlipressin versus placebo on renal function and survival of patients with HRS have been recently reported [66-67]; we identified five studies ( $n=243$ patients) in our meta-analysis [66]. We observed a significant increase in reversal of hepatorenal syndrome among study (terlipressin) versus placebo patients; the pooled OR of HRS reversal rate was 8.09 (95\% CI, 3.521; 18.59; $P=0.0001$ ) [66]. No impact of terlipressin use on survival was noted, pooled OR for survival rate 2.064; 95\% CI, 0.939; $4.538(P=0.07)$ [66].

In their systematic review of randomized trials on vasosoconstrictor drugs for HRS ( $n=376$ patients) the Cochrane Hepato-Biliary Group found that vasoconstrictor drugs reduced mortality compared with no intervention at 15 days only (RR, 0.60 ; 95\% Confidence Intervals, 0.37-0.97) [68]. The presence of a link between terlipressin therapy and survival over the short-term only may be explained by taking account that the prognosis in HRS population is largely dependent upon the degree of liver failure. A significant impairment of liver function is a poor predictor for the response to terlipressin but also for their overall survival [69]. 


\section{Kidney Blood Pressure Research}

Table 2. Baseline characteristics of RCTs (Terlipressin versus Noradrenaline)

\begin{tabular}{lccc}
\hline & Alessandria C., et al. & Sharma P., et al. & Singh V., et al. \\
\hline Publication year & 2007 & 2008 & 2012 \\
Reference number & 34 & 35 & 36 \\
Country & Italy & India & India \\
Patients, $n$ & $12 / 10$ & $20 / 20$ & $23 / 23$ \\
Type 1 HRS pts, $n$ & $5(42 \%) / 4(40 \%)$ & $20(100 \%) / 20(100 \%)$ & $23(100 \%) / 23(100 \%)$ \\
Age, yrs & $55 \pm 2 / 56 \pm 3$ & $47.8 \pm 9.8 / 48.2 \pm 13.4$ & $51.4 \pm 11.6 / 48.3 \pm 11.6$ \\
Men, $n$ & $9(75 \%) / 7(70 \%)$ & $17(85 \%) / 17(85 \%)$ & $19(83 \%) / 19(83 \%)$ \\
Alcoholic cirrhosis, $n$ & $4(33 \%) / 2(20 \%)$ & $14(70 \%) / 12(60 \%)$ & $10(43 \%) / 12(52 \%)$ \\
Serum creatinine, mg/dL & $2.5 \pm 0.3 / 2.3 \pm 0.2$ & $3 \pm 0.5 / 3.3 \pm 1.3$ & $3.2 \pm 0.7 / 3.1 \pm 0.6$ \\
Child-Pugh score & $11 \pm 1 / 10 \pm 1$ & $10.6 \pm 0.8 / 11 \pm 0.9$ & $10.7 \pm 2 / 10.4 \pm 1.7$ \\
Responders, $n$ & $10(83 \%) / 7(70 \%)$ & $10(50 \%) / 10(50 \%)$ & $9(39 \%)) / 10(43 \%)$ \\
\hline Figures are given for terlipressin $/$ noradrenaline patient groups wherever appropriate
\end{tabular}

Figures are given for terlipressin/ noradrenaline patient groups wherever appropriate

\section{Therapy of HRS: Arterial blood pressure and vasoconstrictors}

Although the purpose of vasoconstrictor therapy in HRS is to specifically optimize renal haemodynamics, this effect is typically achieved with a concomitant increase in systemic blood pressure. A pooled analysis of 21 clinical studies ( $n=501$ patients) revealed that an increase in mean arterial pressure is strongly associated with a decline in serum creatinine (rho $=-0.76, P<0.001$ ) [70]. On average, for every $1-\mathrm{mmHg}$ increase in MAP, a 0.12 $\mathrm{mg} / \mathrm{dL}$ decline in serum creatinine is expected; every $8.6 \mathrm{mmHg}$ increase in MAP is associated with a $1.0 \mathrm{mg} / \mathrm{dL}$ decline in serum creatinine. The authors suggested that, independent of which vasoconstrictor is chosen, targeting a systematic rise in MAP of around 10-15 mmHg during vasoconstrictor therapy may lead to more favourable kidney outcomes. Most studies included in this review tested terlipressin as vasoconstrictor; two papers addressed norepinephrine. Physicians have been so far reluctant to adopt norepinephrine due to the fear of aggravating renal hypoperfusion, norepinephrine induces afferent arteriolar vasoconstriction through $\alpha_{1}$ adrenergic receptor stimulation. Some small-sized RCTs have recently reported that noradrenaline may be a good alternative to terlipressin in improving renal function [35-38] (Table 2). Our preliminary meta-analysis of some RCTs ( $n=108$ unique patients) showed that the pooled Odds Ratio of HRS reversal after vasoconstrictor therapy was 0.96 (95\% CI, 0.45; 2.07, NS), as listed in the Galbraith plot (Figure 2). In other words, noradrenaline and terlipressin were equally effective in the treatment of HRS. All these studies calculated that noradrenaline was less expensive than terlipressin. It has been speculated that norepinephrine increases the mean arterial pressure by its $\alpha_{1}$-mediated effect on systemic vascular resistance and its $\beta_{1}$-mediated inotropic activity; these activities overcoming its local effects on renal circulation.

\section{Therapy of HRS: TIPS}

In addition to vasoconstrictor therapy, an alternative approach includes TIPS. TIPS is a non-surgical procedure of portal decompression used as an alternative therapy for cirrhotic patients bleeding from oesophageal or gastric varices who do not respond to endoscopic and medical treatment. An interventional radiologist will place a side-to-side portocaval shunt that links the portal and hepatic veins within the hepatic parenchyma. TIPS reduces portal pressure and the filtration in the peritoneal space to a level which can be drained by the lymphatic system. TIPS returns some of the volume of blood pooled in the splanchnic circulation to the systemic circulation.

Within four weeks after TIPS urinary sodium excretion and serum creatinine improve and, in combination with diuretics, can normalise within 6-12 months. This occurs in 


\section{Kidney \\ Blood Pressure Research}

association with increases in urinary volume, glomerular filtration rate, and serum sodium concentration. The activity of vasoconstrictor and anti-natriuretic systems such as RAAS, SNS, and arginine vasopressin (AVP) is lowered and an amelioration of renal circulation occurs.

The effect of TIPS on renal function and haemodynamics has been investigated in various studies on patients with cirrhosis and refractory ascites [71]. TIPS have been proved to be effective even in patients with cirrhosis and parenchymal renal disease

[72]. The role of TIPS in the treatment of HRS has been addressed in a few papers [73-76]; Guevara et al. were the first authors to treat HRS patients by TIPS; renal function strongly improved in 6 of the 7 patients with type-1 HRS [73]. Brensing et al. treated 31 HRS patients (14 type 1 and 17 type 2), 77\% (24/31) exhibited sustained improvement in GFR. Cox regression analysis showed that bilirubin $(P<0.001)$ and HRS type $(P<0.05)$ were independent survival predictors after TIPS [74]. In a recent series of type-1 HRS patients, Testino et al treated with TIPS nine consecutive patients having severe acute alcoholic hepatitis, 30 days after TIPS insertion serum creatinine was $1.6 \pm 0.6$ vs. $5.2 \pm 0.9$ at baseline $(P<0.04)$ [76].

However, there are some drawbacks associated with TIPS including trans-capsular puncture, and shunt stenosis. Patients with advanced cirrhosis are notgood candidates to TIPS procedure as they are at risk for worsening liver failure and/or hepatic encephalopathy. TIPS activity appears to be slow and beneficial in some patients only. Many clinical, biochemical and neuro-humoral parameters improve but do not fully reverse after TIPS insertion.

\section{Therapy of HRS: Dialysis}

Initiation of RRT is controversial in patients with type 1 HRS who are not candidates for liver transplantation due to poor life expectancy and high morbidity /mortality rates associated with RRT. Early studies demonstrated that initiation of RRT in cirrhotic patients is associated with increased mortality due in part to the increased risk of haemorrhage and hypotension [77]. As reported by Keller et al. [78], HRS patients who underwent RRT survived more than those who did not receive RRT but 33\% of the days gained were spent in the hospital.

For HRS patients who are non-responder to vasoconstrictors or TIPS and are waiting for a liver transplant or are being evaluated for OLT, RRT should be considered a good choice [77]. The decision between intermittent haemodialysis or continuous renal replacement therapy should be individualized as evidence currently shows that neither has been shown to be superior to the other, even if CRRT is probably better tolerated in unstable patients [79-82].

Newer approaches are currently under evaluation for HRS patients including the extracorporeal albumin dialysis (MARS) or the Prometheus system. MARS (molecular adsorbent recirculation system) is designed to make clearance of albumin-bound toxins (i.e., bile acids) and water-soluble cytokines (i.e., IL-6) which have been implicated in the HRS pathogenesis. In a randomized study, Mitzner et al. [83] showed that MARS was
Fig. 2.

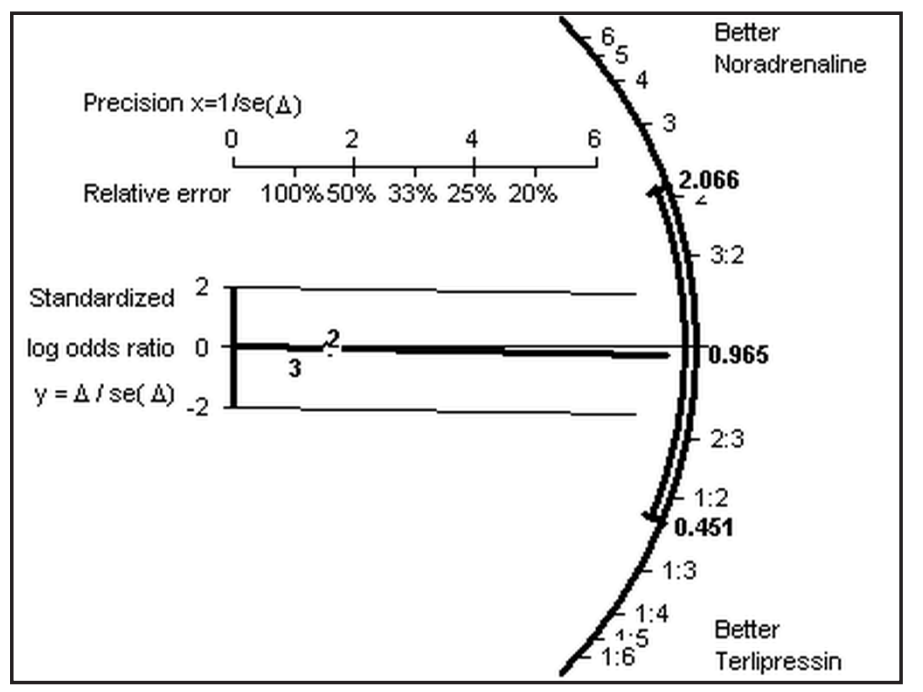




\section{Kidney \\ Blood Pressure Research}

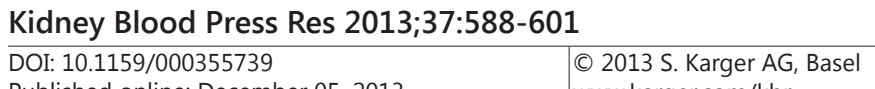

Published online: December 05, 2013

www.karger.com/kbr

Fabrizi/Aghemo/Messa: Therapy of Hepato-Renal Syndrome

superior to CRRT in type 1 HRS patients in terms of patient survival, improved clinical and biochemical parameters were also found. A more recent study demonstrated that MARS was ineffective in improving systemic haemodynamics in six patients with type 1 HRS who failed vasoconstrictor treatment; only transient reduction in serum creatinine occurred [84]. Another study on 32 HRS-1 patients reported a rate of complete renal response of $28 \%$ (9/32) [85]. Prometheus employs fractional plasma separation, and adsorption with haemodialysis could be utilized to treat liver failure patients who have a need for RRT. It has not yet been studied in HRS population and has been used in hepatic failure. MARS and Prometheus may work as a bridge to OLT but they should be considered experimental approaches until controlled studies will be done.

\section{Conclusions}

Hepatorenal syndrome remains frequent among patients with end stage liver disease. The main clinical manifestations include renal failure (with low urine output) and sodium and water retention (with ascites, edema and dilutional hyponatremia). Occurrence of HRS is associated with a lower survival before and after LT, compared to non-HRS patients. Liver transplantation is the preferred treatment for HRS. Terlipressin is a vasopressin analogue which improves renal perfusion by inducing vasoconstriction of the splanchnic circulation. Convincing evidence has been given over the recent years showing that the combined therapy (terlipressin with albumin) has really improved the prognosis of HRS patients. Continuous treatment with terlipressin until liver transplantation in patients with HRS recurrence after the first treatment is a good option as a bridge to liver transplantation. Combination therapy (terlipressin plus albumin) should be improved with the aim to reduce the rate of nonresponder or relapser patients. RRT should be offered as a bridge to patients awaiting liver transplant or those undergoing liver transplant evaluation.

\section{Abbreviations}

HRS: hepatorenal syndrome; IAC: International Ascites Club; LT: liver transplantation; MAP: mean arterial pressure; MARS: molecular adsorbent recirculating system; NSAIDs: non steroidal anti-inflammatory drugs; OR: Odds Ratio; PRA: plasma renin activity; RAAS: reninangiotensin- aldosterone system; RCT: randomized controlled trials; RRT: renal replacement therapy; SBP: spontaneous bacterial peritonitis; SNS: sympathetic nervous system; TIPS: transjugular intra-hepatic porto-systemic stent shunt.

\section{Acknowledgements}

This work has been supported in part by the grant 'Project Glomerulonephritis', in memory of Pippo Neglia

\section{References}

1 Frerichs FT: Tratado practico de las Enfermedades del Higado, de los Vasos Hepaticos y de las Vias Biliares. Madrid: Libreria Extranjera y Nacional, Scientifica y Literaria, 1877.

-2 Wilensky AO: Occurrence, distribution and pathogenesis of so called liver death and/or hepatorenal syndrome. Arch Surg 1939;38:625-691.

3 Orr T, Helwig F: Liver trauma and the hepatorenal syndrome. Ann Surg 1939;110:683-692.

4 Hecker R, Sherlock S: Electrolyte and circulatory changes in terminal liver failure. Lancet 1956;2:12211225. 


\section{Kidney \\ Blood Pressure Research}

Fabrizi/Aghemo/Messa: Therapy of Hepato-Renal Syndrome

5 Koppel M, Coburn J, Mims M, Goldstein H, Boyle J, Rudini M: Transplantation of cadaveric kidneys from patients with hepatorenal syndrome. Evidence for the functional nature of renal failure in advanced liver disease. N Engl J Med 1969;280:1367-1371.

6 Arroyo V, Gines P, Gerbes A, Dudley F, Gentilini P, Laffi G, Reynolds T, Ring-Larsen H, Scholmerich J: Definition and diagnostic criteria of refractory ascites and hepatorenal syndrome in cirrhosis. Hepatology 1996;23:164-176.

7 Salerno F, Gerbes A, Gines P, Wong F, Arroyo V: Diagnosis, prevention, and treatment of hepatorenal syndrome in cirrhosis. Gut 2007;56:1310-1318.

Angeli P, Morando F, Cavallin M, Piano S: Hepatorenal syndrome. Contrib Nephrol 2011;174:46-55.

Gines P, Guevara M, Arroyo V, Rodes J: Hepatorenal syndrome. Lancet 2003;362:1819-1827.

10 Gines A, Escorsell A, Gines P, Salo J, Jimenez W, Inglada L: Incidence, predictive factors, and prognosis of the hepatorenal syndrome in cirrhosis with ascites. Gastroenterology 1993;105:229-236.

11 Pham P, Pham P, Rastogi A, Wilkinson A: Review article: current management of renal dysfunction in the cirrhotic patient. Aliment Pharmacol Ther 2005;21:949-961.

12 Wadei H, Mai M, Ahsan N, Gonwa T: Hepatorenal syndrome: Pathophysiology and management. Clin J Am Soc Nephrol 2006;1:1066-1079.

13 Genzini T, Torricelli F: Hepatorenal syndrome: an update. San Paulo Med J 2007;125:1-14.

14 Arroyo V, Terra C, Ginès P: Advances in the pathogenesis and treatment of type-1 and type-2 hepatorenal syndrome. J Hepatol 2007;46:935-946.

15 Schrier R, Arroyo V, Bernardi M, Epstein M, Henriksen J, Rodes J: Peripheral arterial vasodilatation hypothesis: a proposal for the initiation of renal sodium and water retention in cirrhosis. Hepatology 1988;8:1151-1157.

16 Alqahtani A, Fouad T, Lee S: Cirrhotic cardiomyopathy. Sem Liv Dis 2008;28:59-69.

17 Trawalè J, Paradis V, Rautou P, Francoz C, Escolano S, Sallèe M, Durand F, Valla D, Lebrec D, Moreau R: The spectrum of renal lesions in patients with cirrhosis: a clinicopathological study. Liver Intern 2010;30:725732.

18 Distant D, Gonwa T: The kidney in liver transplantation. J Am Soc Nephrol 1993;4:129-136.

$\checkmark 19$ Gonwa TA, Morris CA, Goldstein RM, Husberg BS, Klintmalm GB: Long-term survival and renal function following liver transplantation in patients with and without hepatorenal syndrome - experience in 300 patients. Transplantation 1991;51:428-430 .

20 Ruiz R, Barri Y, Jennings L, Chinnakotla S, Goldstein R, Levy M, McKenna G, Randall H, Sanchez E, Klintmalm G: Hepatorenal syndrome: a proposal for kidney after liver transplantation. Liver Transplant 2007;13:838-843.

21 Gonwa AT, Klintmalm GB, Levy M, Jennings LS, Goldstein RM, Husberg BS: Impact of pre-transplant renal function on survival after liver transplantation. Transplantation 1995;93:148-156.

22 Fabrizi F, Martin P, Messa P: Recent advances in the management of hepatorenal syndrome. Acta Clinica Belg 2007;62:S393-S396.

-23 Cardenas A: Hepatorenal syndrome: A dreaded complication of end-stage liver disease. Am J Gastroenterol 2005;100:460-467.

-24 Lata J: Hepatorenal syndrome. World J Gastroenterol 2012;28:4978-4984.

25 Giostra E, Ruedin P, Cunningham M, Mentha G, Favre H, Jolliet P, Chevrolet J: Sustained effects of ornipressin in hepatorenal syndrome. J Hepatol 1995;22:120-121.

26 Guevara M, Gines P, Fernandez-Esparrach G, Sort P, Salmeron JM, Jimenez W, Arroyo V, Rodes J: Reversibility of hepatorenal syndrome by prolonged administration of ornipressin and plasma volume expansion. Hepatology 1998;27:35-41.

27 Gulberg V, Bilzer M, Gerbes AL: Long-term therapy and retreatment of hepatorenal syndrome type 1 with ornipressin and dopamine. Hepatology 1999;30:870-875.

28 Kaffy F, Borderie C, Chagneau C, Ripault M, Larziliere I, Silvain C, Beauchant M: Octreotide in the treatment of hepatorenal syndrome in cirrhotic patients. J Hepatol 1999;30:174.

29 Angeli P, Volpin R, Gerunda G, Craighero R, Roner P, Merenda R, Amodio P, Sticca A, Caregaro L, MaffeiFacioli A, Gatta A: Reversal of type 1 hepatorenal syndrome with the administration of midodrine and octreotide. Hepatology 1999;29:1690-1697.

-30 Pomier-Layrargues G, Paquin SC, Hassoun Z, Lafortune M, Tran A: Octreotide in hepatorenal syndrome: A randomized, double-blind, placebo-controlled, crossover study. Hepatology 2003;38:238-243. 


\section{Kidney \\ Blood Pressure Research}

\begin{tabular}{l|l}
\hline Kidney Blood Press Res 2013;37:588-601 \\
\hline DOI: $10.1159 / 000355739$ & (c) 2013 S. Karger AG, Basel
\end{tabular}

Published onlıne: December 05, 2013

www.karger.com/kbr

Fabrizi/Aghemo/Messa: Therapy of Hepato-Renal Syndrome

-31 Kiser T, Fish D, Obritsch M, Jung R, MacLaren R, Parikh C: Vasopressin, not octreotide, may be beneficial in the treatment of hepatorenal syndrome: a retrospective study. Nephrol Dial Transplant 2005;20:18131820.

-32 Esrailian E, Pantangco ER, Kyulo NL, Hu KQ Runyon BA: Octreotide/ Midodrine therapy significantly improves renal function and 30-day survival in patients with type 1 hepatorenal syndrome. Dig Dis Sci 2007;52:742-748.

-33 Durkin R, Winter S: Reversal of hepatorenal syndrome with the combination of norepinephrine and dopamine. Crit Care Med 1995;23:202-204.

-34 Duvoux C, Zanditenas D, Hezode C, Chauvat A, Monin J, Roudot-Thoraval F, Mallat A, Dhumeaux D: Effects of noradrenalin and albumin in patients with type 1 hepatorenal syndrome. A pilot study. Hepatology 2002;36:374-380.

35 Alessandria C, Ottobrelli A, Debernardi-Venon W, Todros L, Torrani Cerenzia M, Martini S, Balzola F, Morgando A, Rizzetto M, Marzano A: Noradrenalin versus terlipressin in patients with hepatorenal sindrome: A prospective, randomized, unblinded, pilot study. J Hepatol 2007;47:499-505.

-36 Sharma P, Kumar A, Shrama BC, Sarin KV: An open label, pilot, randomized controlled trial of noradrenaline versus terlipressin in the treatment of type 1 hepatorenal syndrome and predictors of response. Am J Gastroenterol 2008;103:1-9.

37 Singh V, Ghosh S, Singh B, Kumar P, Sharma N, Bhalla A, Sharma A, Choudhary N, Chawla Y, Nain C: Noradrenalin vs. terlipressin in the treatment of hepatorenal syndrome: A randomized study. J Hepatol 2012;56:1293-1298.

38 Ghosh S, Choudhary N, Sharma K, Singh B, Kumar P, Agarwal R, Sharma N, Bhalla A, Chawla Y, Singh V: Noradrenaline vs. terlipressin in the treatment of type 2 hepatorenal syndrome: a randomized pilot study. Liver Intern 2013;33:1187-1193.

39 Ganne-Carie N, Hadengue A, Mathurin P, Durand F, Erlinger S, Benhamou J: Hepatorenal syndrome. Longterm treatment with terlipressin as a bridge to liver transplantation. Dig Dis Sci 1996;41:1054-1056.

40 Hadengue A, Gadano A, Moreau R, Giostra E, Durand F, Valla D, Erlinger S, Lebrec D: Beneficial effects of the 2-day administration of terlipressin in patients with cirrhosis and hepatorenal syndrome. J Hepatol 1998;29:565-570.

41 Le Moine O, el Nawar A, Jagodzinski R, Bourgeois N, Adler M, Gelin M, Cremer M: Treatment with terlipressin as a bridge to liver transplantation in a patient with hepatorenal syndrome. Acta Gastroenterol Belg 1998;61:268-270.

42 Duhamel C, Mauillon J, Berkelmans I, Bourienne A, Tranvouez J: Hepatorenal syndrome in cirrhotic patients: terlipressin is a safe and efficient treatment;propanolol and digital treatments: precipitating and preventing factors? Am J Gastroenterol 2000;95:2984-2985.

43 Uriz J, Gines P, Cardenas A, Sort P, Jimenez W, Salmeron J, Bataller R, Mas A, Navasa M, Arroyo V, Rodes J: Terlipressin plus albumin infusion: an effective and safe therapy of hepatorenal syndrome. J Hepatol 2000;33:43-48.

44 Mulkay J, Louis H, Donckier V, Bourgeois N, Adler M, Deviere J, Le Moine O: Long-term terlipressin administration improves renal function in cirrhotic patients with type 1 hepatorenal syndrome: a pilot study. Acta Gastroenterol Belg 2001;LXIV:15-19.

45 Yang Y, Dan Z, Liu N, Liu M: Efficacy of terlipressin in the treatment of liver cirrhosis with hepatorenal syndrome. J Int Medicine 2001;7:123-125.

46 Ortega R, Ginès P, Uriz J, Cardenas A, Calahorra B, De Las Heras D, Guevara M, Bataller R, Jimenez W, Arroyo V, Rodes J: Terlipressin therapy with and without albumin for patients with hepatorenal syndrome: Results of a prospective, non randomised study. Hepatology 2002;36:941-948.

47 Halimi C, Bonnard P, Bernard B, Mathurin P, Mofredj A, Di Martino V, Demontis R, Henry-Biabaud E, Fievet P, Opolon P, Poynard T, Cadranel J: Effect of terlipressin (glypressin) on hepatorenal syndrome in cirrhotic patients: results of a multicentre pilot study. Eur J Gastroenterol Hepatol 2002;14:153-158.

48 Colle I, Durand F, Pessione F, Rassiat E, Bernuau J, Barriere E, Lebrec D, Valla D, Moreau R: Clinical course, predictive factors, and prognosis in patients with cirrhosis and type 1 hepatorenal syndrome treated with terlipressin: a retrospective analysis. J Gastroenterol Hepatol 2002;17:882-888. 


\section{Kidney \\ Blood Pressure Research}

Kidney Blood Press Res 2013;37:588-601

DOI: 10.1159/000355739
Published onlIne: December 05, 2013

Fabrizi/Aghemo/Messa: Therapy of Hepato-Renal Syndrome

49 Moreau R, Durand F, Poynard T, Duhamel C, Cervoni JP, Ichai P, Abergel A, Halimi C, Pauwels M, Bronowicki JP, Giostra E, Fleurot C, Gurnot D, Nouel O, Renard P, Rivoal M, Blanc P, Coumaros D, Ducloux S, Levy S, Pariente A, Perarnau JM, Roche J, Scribe-Outtas M, Valla D, Bernard B, Samuel D, Butel J, Hadengue A, Platek A, Lebrec D, Cadranel JF: Terlipressin in patients with cirrhosis and type 1 hepatorenal syndrome: A retrospective multicenter study. Gastroenterology 2002;122:923-930.

-50 Moreau R, Asselah T, Condat B, de Kergenuenec C, Pessione F, Bernard B, Poynard T, Binn M, Grangè J, Valla D, Lebrec D: Comparison of the effect of terlipressin and albumin on arterial blood volume in patients with cirrhosis and tense ascites treated by paracentesis: a randomised pilot study. Gut 2002;50:90-94.

51 Alessandria C, Debernardi Venon W, Marzano A, Barletti C, Fadda M, Rizzetto M: Renal failure in cirrhotic patients: role of terlipressin in clinical approach to hepatorenal syndrome type 2. Eur J Gastroenterol Hepatol 2002;14:1363-1368.

52 Saner F, Fruhaut N, Schafers R, Lang H, Malagò M, Broelsch C: Terlipressin plus hydroxyethyl starch infusion: an effective treatment for hepatorenal syndrome. Eur J Gastroenterol Hepatol 2003;15:925-927.

53 Solanki P, Chawla A, Garg R, Gupta R, Jain M, Sarin SK: Beneficial effects of terlipressin in hepatorenal syndrome: A prospective, randomized placebo-controlled clinical trial. J Gastroenterol Hepatol 2003;18:152-156.

54 Saner F, Kavuk I, Lang H, Biglarnia R, Fruhauf R, Schafers R, Malagò M, Broelsch C: Terlipressin and gelafundin: safe therapy of hepatorenal syndrome. Eur J Med Res 2004;9:78-82.

55 Kalambokis G, Economou M, Paraskevi K, Konstantinos P, Pappas C, Katsaraki A, Tsianos E: Effects of somatostatin, terlipressin and somatostatin plus terlipressin on portal and systemic hemodynamics and renal sodium excretion in patients with cirrhosis. J Gastroenterol Hepatol 2005;20:1075-1081.

56 Neri S, Pulvirenti D, Malaguarnera M, Cosimo BM, Bertino G, Ignaccolo L, Siringo S, Castellino P: Terlipressin and albumin in patients with cirrhosis and type 1 hepatorenal sindrome. Dig Dis Sci 2008;53:830-835.

57 Ng C, Chan M, Tai M, Lam C: Hepatorenal syndrome. Clin Biochem Rev 2007;28:11-17.

-58 Schoening W, Buecker N, Rademacher S, Andreou A, Kuehn S, Neuhaus R, Guckelbuger O, Puhl G, Seehofer D, Neuhaus P: Twenty-year longitudinal follow-up after orthotopic liver transplantation: a single-center experience of 313 consecutive cases. Am J Transplant 2013;13:2384-2394.

59 Restuccia T, Ortega R, Guevara M, Gines P, Alessandria C, Ozdogan O, Navasa M, Rimola A, Garcia-Valdecasas JC, Arroyo V, Rodes J: Effects of treatment of hepatorenal sindrome before transplantation on posttransplantation outcome. A case-control study. J Hepatol 2004;40:140-146.

60 Fabrizi F, Dixit V, Martin P: Meta-analysis: terlipressin therapy for the hepatorenal syndrome. Aliment Pharmacol Ther 2006;24:935-944.

61 Piano S, Morando F, Fasolato S, Cavallin M, Boscato N, Boccagni P, Zanus G, Cillo U, Gatta A, Angeli P: Continuous recurrence of type 1 hepatorenal syndrome and long-term treatment with terlipressin and albumin: a new exception to MELD score in the allocation system to liver transplantation ? J Hepatol 2011;55:491-496.

62 Caraceni P, Santi L, Mirici F, Montanari G, Bevilacqua V, Pinna A, Bernardi M: Long-term treatment of hepatorenal syndrome as a bridge to liver transplantation. Dig Liver Dis 2011;43:242-245.

63 Lee JS, Lee HS, Jung SW, Han WS, Kim MJ, Lee SW, Choi JH, Kim CD, Ryu HS, Hyun JH: A case of peripheral ischemic complication after terlipressin therapy. Korean J Gastroenterol 2006;47:454-457 .

64 Martin-Llahi M, Pepin MN, Guevara M, Diaz F, Torre A, Monescillo A, Soriano G, Terra C, Fabrega E, Arroyo V, Rodes J, Gines P: Terlipressin and albumin vs. albumin in patients with cirrhosis and hepatorenal syndrome: A randomized study. Gastroenterology 2008;134:1352-1359.

65 Sanyal A, Boyer T, Garcia-Tsao G, Regenstein F, Rossaro L, Appenrodt B, Blei A, Gulberg V, Sigal S, Teuber $\mathrm{P}$ : A randomized, prospective, double-blind, placebo-controlled trial of terlipressin for type 1 hepatorenal syndrome. Gastroenterology 2008;134:1360-1368.

66 Fabrizi F, Dixit V, Messa P, Martin P: Terlipressin for hepatorenal syndrome: A meta-analysis of randomized trials. Int J Artif Organs 2009;32:133-140.

67 Sagi S, Mittal S, Kasturi K, Sood G: Terlipressin therapy for reversal of type 1 hepatorenal syndrome: A meta-analysis of randomized controlled trials. J Gastroenterol Hepatol 2010;25:880-885.

-68 Gluud L, Christensen K, Christensen E, Kraig A: Systematic review of randomized trials on vasoconstrictor drugs for hepatorenal syndrome. Hepatology 2010;51:576-584. 


\section{Kidney \\ Blood Pressure Research}

Fabrizi/Aghemo/Messa: Therapy of Hepato-Renal Syndrome

69 Moreau R, Lebrec D: The use of vasoconstrictors in patients with cirrhosis: type 1 HRS and beyond. Hepatology 2006;43:385-394.

70 Velez J, Nietert P: Therapeutic response to vasoconstrictors in hepatorenal syndrome parallels increase in mean arterial pressure: a pooled analysis of clinical trials. Am J Kidney Dis 2011;58:928-938.

71 Rossle M, Gerbes A: TIPS for the treatment of refractory ascites, hepatorenal syndrome and hepatic hydrothorax: a critical update. Gut 2010;59:988-1000.

72 Hollò S, Pacitti A, Ottobrelli A, Torrani M, Lavezzo B, Damiani D, Triolo G, Piccoli G: Acute renal failure treatment in liver cirrhosis: the role of transjugular intrahepatic portosystemic shunts. Giorn It Nefrol 2001, 18:666-672.

-73 Guevara M, Ginès P, Bandi J, Gilabert R, Sort P, Jimenez W, Garcia-Pagan J, Bosch J, Arroyo V, Rodes J: Transjugular intrahepatic portosystemic shunt in hepatorenal syndrome: effects on renal function and vasoactive systems. Hepatology 1998;28:416-422.

-74 Brensing K Textor J, Perz J, Schiedermaier P, Raab P, Strunk H, Klehr H, Kramer H, Spengler U, Schild $\mathrm{H}$, Sauerbruch T: Long term outcome after transjugular intraepatic portosystemic stent-shunt in nontransplant cirrhotics with hepatorenal syndrome: a phase 2 study. Gut 2000;47:288-295.

75 Testino G, Ferro C, Sumberaz A, Messa P, Morelli N, Guadagni B, Ardizzone G, Valente G: Type-2 hepatorenal syndrome and refractory ascites: Role of transjugular intrahepatic portosystemic stent-shunt in eighteen patients with advanced cirrhosis awaiting orthotopic liver transplantation. Hepato-Gastroenterol 2000;50:1753-1755.

76 Testino G, Leone S, Ferro C, Borro P: Severe acute alcoholic hepatitis and hepatorenal syndrome: role of transjugular portosystemic stent shunt. J Med Life 2012;5:203-205.

77 Gonwa T, Wadei H: The challenges of providing renal replacement therapy in decompensated liver cirrhosis. Blood Purif 2012;33:144-148.

-78 Keller F, Heinze H, Jochimsen F, Passfall J, Schuppan D, Buttner P: Risk factors and outcome of 107 patients with decompensated liver disease and acute renal failure: The role of haemodialysis. Renal Fail 1995;17:135-146.

79 Davenport A: Renal replacement therapy in the patient with acute brain injury. Am J Kidney Dis 2001;37:457-466.

80 Davenport A, Will E, Davison A: Effect of renal replacement therapy on patients with combined acute renal and fulminant hepatic failure. Kidney Int 1993;41:S245-S251.

81 Gonwa T, Mai M, Melton L, Hays S, Goldstein R, Levy M, Klintmalm G: Renal replacement therapy and orthotopic liver transplantation: The role of continuous veno-venous haemodialysis. Transplantation 2001;71:1424-1428.

82 Witzke O, Baumann M, Patschan D, Patschan S, Mitchell A, Treichel U, Gerken G, Philipp T, Kribben A: Which patients benefit from haemodialysis therapy in hepatorenal syndrome? J Gastroenterol Hepatol 2004;19:1369-1373.

83 Mitzner SR, Stange J, Klammt S, Risler T, Erley C, Bader B, Berger E, Lauchart W, Peszynski P, Freytag J, Hickstein H, Loock J, Lohr J, Liebe S, Emmrich J, Korten G, Schmidt R: Improvement of hepatorenal syndrome with extracorporeal albumin dialysis MARS: Results of a prospective, randomized, controlled clinical trial. Liver Transpl 2000;6:277-286.

84 Wong F, Raina N, Richardson R: Molecular adsorbent recirculating system is ineffective in the management of type 1 hepatorenal syndrome in patients with cirrhosis and ascites who have failed vasoconstrictor treatment. Gut 2010;59:381-386.

-85 Lavayssiere L, Kallab S, Cardeau-Desangles I, Nogier M, Cointault O, Barange K, Muscari F, Rostaing L, Kamar N: Impact of molecular adsorbent recirculating system on renal recovery in type-1 hepatorenal syndrome patients with chronic liver failure. J Gastroenterol Hepatol 2013;28:1019-1024. 